\title{
Study of the effect of carbonation on concrete produced with vegetable fiber (buriti)
}

\section{Murilo Ferreira dos Santos ${ }^{1}$, Renato Acriz de Menezes $^{2}$, Evailton Arantes de Oliveira ${ }^{3}$, Eloadir Afonso Reis Brasil Filho ${ }^{4}$, Darlei dos Anjos Lavor ${ }^{5}$}

\author{
${ }^{1}$ Student of Civil Engineering - Northern University Center (UNINORTE) - Manaus-AM. \\ ${ }^{2}$ Master in Civil Engineering - Federal University of Uberlandia (UFU) - Uberlandia-MG. \\ ${ }^{3}$ Dortorado in progress in PhD, Program in Ecology and Environmental Health - University Fernando Pessoa (UFP) - Porto - Portugal. \\ ${ }^{4}$ Bachelor's Degree in Civil Engineering - Northern University Center (UNINORTE) - Manaus-AM. \\ ${ }^{5}$ Laboratory Technician I - Northern University Center (UNINORTE) - Manaus-AM.
}

Email: mullsantos@gmail.com, renatoufu@ hotmail.com, arantestop@hotmail.com, eloadir_brasil@hotmail.com, darleilavor27@gmail.com

Received: January $15^{\text {th }}, 2018$.

Accepted: February $20^{\text {th }}, 2018$.

Published: March $30^{\text {th }}, 2018$.

Copyright (C2016 by authors and Institute of Technology Galileo of Amazon (ITEGAM).

This work is licensed under the Creative Commons Attribution International

License (CC BY 4.0).

http://creativecommons.org/licenses/by/4.0/ (c) (i) (3) Open Acetes:

\begin{abstract}
This article is based on the production of concrete with vegetable fiber (buriti), emphasizing the effect of carbonation as a form of prevention in relation to pathological causes caused in reinforced concrete. The structuring of this project is done through the preparation of a conventional concrete as the basis of the study to be applied as addition and / or replacement of cement in $0.5 \%$ and $1.0 \%$ of buriti fiber. After the rupture at 28 days, these materials were exposed and the chemical indicator of phenolphthalein was applied to be observed at 7, 28,63, 91 and 120 of the spray.
\end{abstract}

Keywords: Concrete, Buriti Fiber, Carbonation.

\section{Estudo do efeito da carbonatação no concreto produzido com fibra vegetal (buriti)}

\section{RESUMO}

Este artigo está fundamentado na produção do concreto com fibra vegetal (buriti), dando ênfase no efeito da carbonatação como forma de prevenção em relação às causas patológicas ocasionadas em concreto armado. A estruturação deste projeto é dada através da confecção de um concreto convencional como base do estudo para que fosse aplicado como adição e/ ou substituição do cimento em $0,5 \%$ e $1,0 \%$ da fibra de buriti. Após a ruptura aos 28 dias, esses materiais foram expostos e aplicados o indicador químico de fenolftaleína para que fossem observados em 7, 28, 63, 91 e 120 da aspersão.

Palavras Chaves: Concreto, Fibra de Buriti, Carbonatação

\section{INTRODUÇÃO}

Um dos grandes desafios da construção civil trata-se da durabilidade das estruturas de concreto armado [1]. A durabilidade e a vida útil da estrutura dependem, além das características do concreto e de fatores de execução, fundamentalmente das condições ambientais às quais será submetido.

A carbonatação é um dos mecanismos mais correntes de deterioração do betão armado [2]. O dióxido de carbono presente no ar penetra nos poros do betão e reage com o hidróxido de cálcio formando carbonato de cálcio e água. Esse processo é acompanhado pela redução da alcalinidade do betão. Compósitos de fibrocimento também sofrem carbonatação, sendo que há estudos publicados a esse respeito [3]. A carbonatação em telhas de fibrocimento causa retração significativa, de modo que quando estocadas em pilhas por muito tempo, esta retração é diferencial na borda e região central das telhas, causando fissuração de borda [4]. No entanto, nos casos onde não ocorre carbonatação diferencial, os seus efeitos podem ser benéficos, devido à redução da porosidade do material, com ganho de desempenho mecânico [5]. Uma vez que não há armadura metálica nestes compósitos, a redução do pH não é danosa ao material [6]. 
A adição de fibras nas matrizes pode melhorar as suas propriedades mecânicas, como a resistência à tração, à flexão e ao impacto [7]. Além disso, altera seu comportamento após fissuração diminuindo os efeitos de uma ruptura brusca da matriz cimentícia. Escreveram em seu trabalho que nos ultimos anos a produção de artigos e pesquisa referente à compósitos utilizando fibras vegetais aumentou consideravelmente[8]. Entretanto, compósitos reforçados com fibras vegetais ainda estão na dependência de alguns fatores importantes, relacionado a sua aplicação e desempenho. É importante considerar que as fibras vegetais tem composição química diferente e depende do tipo de planta, da dimensão da célula cristalina, do ângulo helicoidal que a celulose faz em relação ao eixo central, defeitos superficiais, estrutura da macrofibra vegetal, propriedades físicas e mecanicas das fibras e a interação que a fibra pode fazer com a matriz do compósito [9].

\section{REVISÃO BIBLIOGRÁFICA}

\section{II.1 FIBRA DA PALMEIRA DE BURITI}

O buriti (Mauritia flexuosa Martius) é a palmeira mais comum e abundante no território brasileiro e encontra-se distribuída em toda a América do Sul [10]. Conhecida como "Árvore da Vida", dela tudo se é aproveitada e muitos moradores de comunidades rurais têm nessa palmeira a sua principal fonte de renda. Em diferentes Estados brasileiros, a fibra retirada das folhas jovens da palmeira de buriti é utilizada na confecção de artesanato, sendo esta parte da fibra conhecida popularmente como "linho ou seda" de buriti.

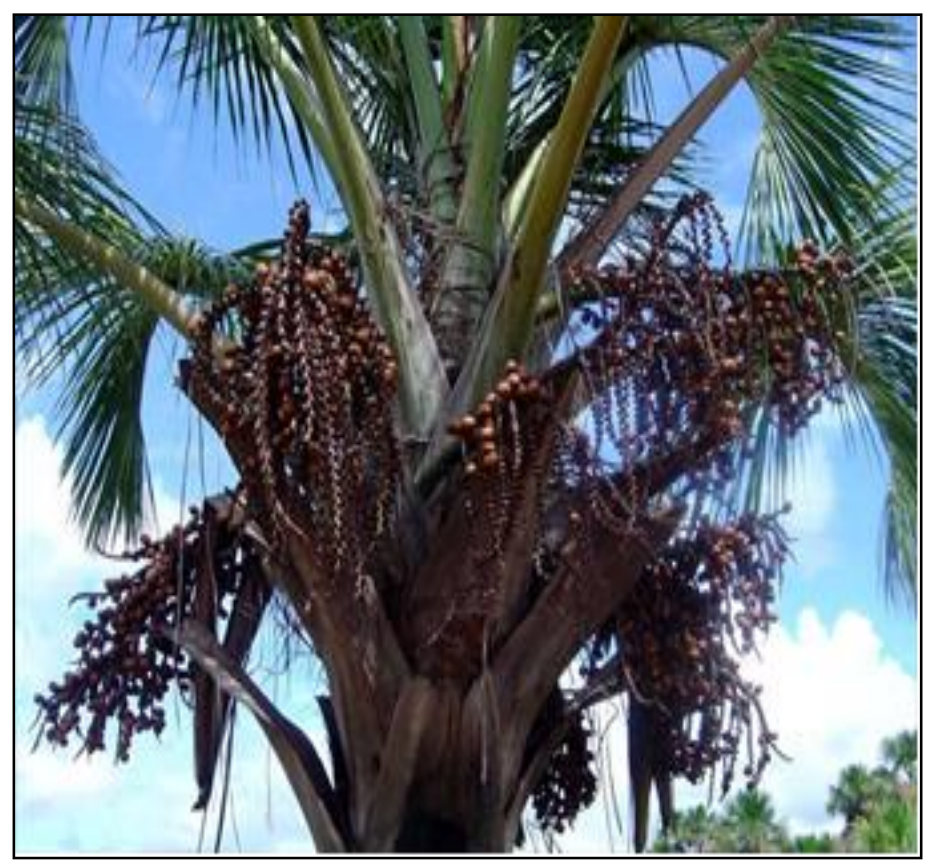

Figura 1: Palmeira de buriti ou Buritizeiro.

Fonte: Adaptado do site G1, (2017).

A coleta das fibras de Buriti foi retirada de forma manual, com a indispensável prévia de lavagem dos fechos, eliminando os resíduos putrifico que pudessem afetar as características para a confecção do concreto.

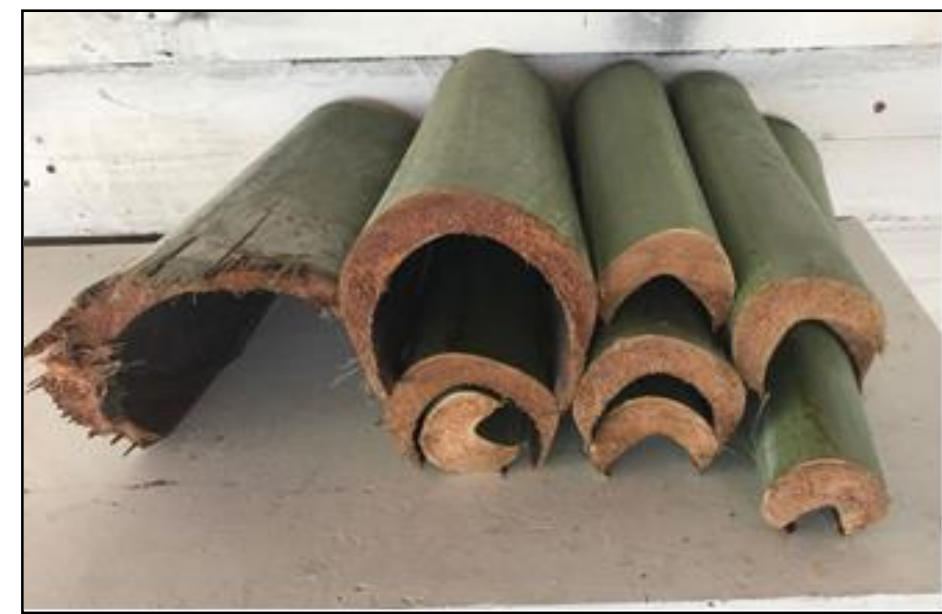

Figura 2: Palmeira de buriti coletada e lavada previamente.

Fonte: Autores, (2018).

\section{II.2 COMPÓSITOS CIMENTÍCIOS COM FIBRA VEGETAL}

A adição de fibras orgânicas (vegetal) em concreto vem ganhando espaço gradativamente como material alternativo para adição e/ ou substituição, pois é um material com um custo baixo comparado com os vários tipos disponíveis no mercado, onde produzem uma excelente flexibilidade e resistencia mecânica às matrizes de concreto [11].

As fibras são materiais com propriedades mecânicas de bastante relevância como a alta resistência e rigidez, além de grande esbeltez e pequenas seções como características geométricas de relevância [12]. O aumento da tenacidade é influenciado pela concentração de fibras e pela resistência das fibras ao arrancamento que por sua vez são governadas pela relação do aspecto (comprimento/ diâmetro) da fibra e por outros fatores como forma ou a textura superficial. Atualmente tem ganhado destaque os Concretos Reforçados com Fibras (CRF) que são utilizados para diversas finalidades, devido as suas propriedades.

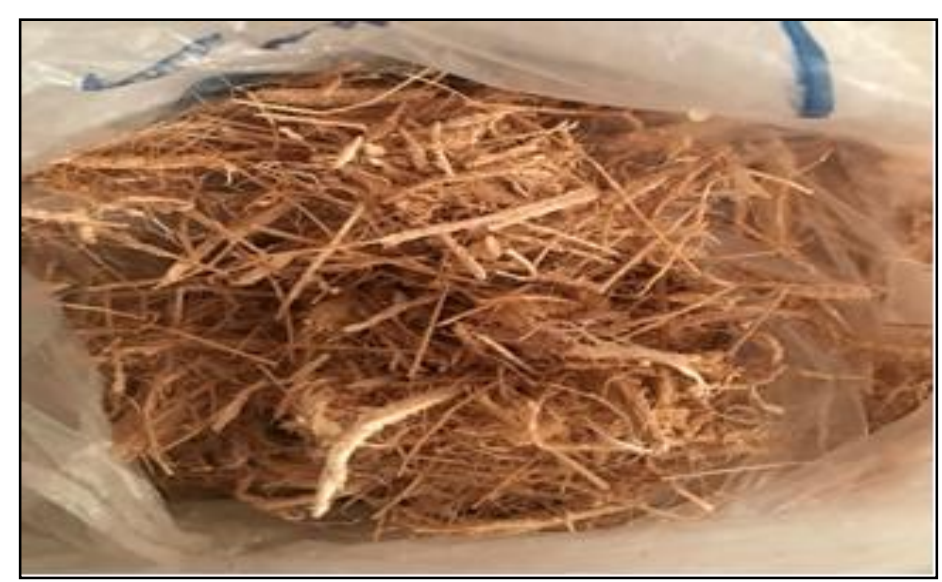

Figura 3: Fibra da palmeira de buriti.

Fonte: Autores, (2018).

\section{II.3 DEFINIÇÃO SOBRE O EFEITO DA CARBONATAÇÃO NO CONCRETO}

A carbonatação é um fenômeno físico-químico decorrente da reação entre os constituintes ácidos do meio com o líquido intersticial existente nos poros do concreto, que se encontra 
saturado por hidróxidos de cálcio provenientes da hidratação do cimento, e também, com outros compostos hidratados do cimento em equilíbrio com o líquido intersticial [13]. O ácido carbônico $\left(\mathrm{H}_{2} \mathrm{CO}^{3}\right)$, o dióxido de enxofre $\left(\mathrm{SO}_{2}\right)$ e o gás sulfídrico $\left(\mathrm{H}_{2} \mathrm{~S}\right)$ são os principais constituintes ácidos do meio.

$\mathrm{O}$ processo de carbonatação ocorre devido às reações do $\mathrm{CO}_{2}$, presente no ar, com os hidróxidos alcalinos presentes no material [14]. Isso ocorre especialmente com o hidróxido de cálcio, em meio aquoso, formando o carbonato de cálcio e reduzindo o $\mathrm{pH}$, inicialmente em torno de 13, para valores próximos a 8 .

\section{MATERIAIS E MÉTODOS \\ III.1 PREMISSAS TÉCNICAS}

As premissas técnicas das atividades para a caracterização dos materiais pertinentes ao concreto foram desenvolvidas atendendo as normas técnicas da Associação Brasileira de Normas Técnicas (ABNT). Todas as análises realizadas atendem os pré-requisitos especificado por norma para que a qualidade do concreto.

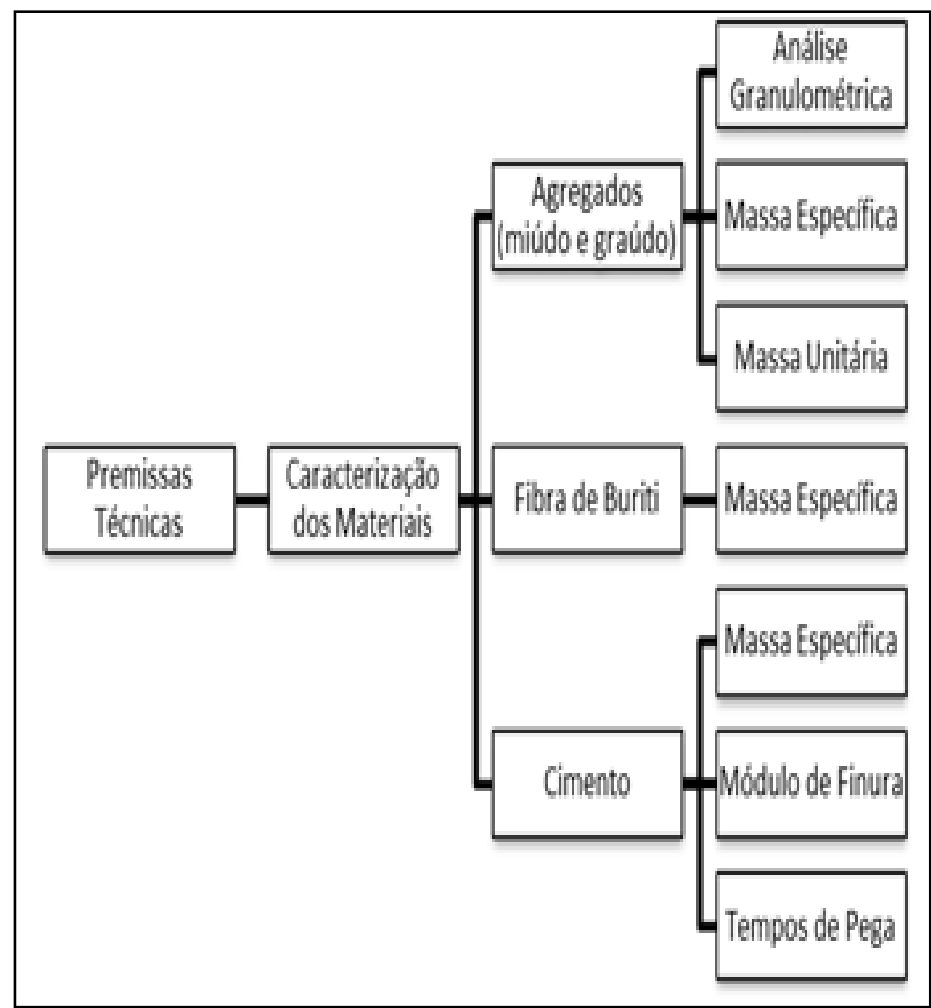

Figura 4: Fluxograma das atividades realizadas para a caracterização dos materiais.

Fonte: Autores, (2018).

\section{2 DOSAGEM DO CONCRETO COM FIBRA DE BURITI}

O método utilizado para o cálculo de dosagem do concreto foi conforme os procedimentos da Associação Brasileira de Cimento Portland (ABCP, 2009); onde se encontrou os seguintes valores para um traço referencial: (1: $0,8: 1,14: 2,34: 0,55)$; do qual foram elaborados mais dois traços com a adição de fibras em $0,5 \%$ e em $1,0 \%$ do material.
Tabela 1: Traço unitário do concreto convencional.

\begin{tabular}{|l|l|}
\hline Concreto & \\
\hline Fck (MPa) & 25 \\
\hline Sd (MPa) & 4 \\
\hline Cimento & \\
\hline Resistência normal aos 28 dias $(\mathrm{MPa})$ & 40 \\
\hline Massa específica $\left(\mathrm{Kg} / \mathrm{m}^{3}\right)$ & 3100,96 \\
\hline Agregado miúdo & \\
\hline Módulo de fínura & 2,51 \\
\hline Massa específica Areia $\left(\mathrm{Kg} / \mathrm{m}^{3}\right)$ & 2620,0 \\
\hline Massa unitána Areia $\left(\mathrm{Kg} / \mathrm{m}^{3}\right)$ & 1560,0 \\
\hline Massa específica Pó de Brita $\left(\mathrm{Kg} / \mathrm{m}^{3}\right)$ & 2620,0 \\
\hline Massa unitária Pó de brita $\left(\mathrm{Kg} / \mathrm{m}^{3}\right)$ & 1580,0 \\
\hline Agregado graúdo & \\
\hline Dimensão máxima característica $(\mathrm{mm})$ & 9,5 \\
\hline Massa específica $\left(\mathrm{Kg} / \mathrm{m}^{3}\right)$ & 2770,0 \\
\hline Massa unitária $\left(\mathrm{Kg} / \mathrm{m}^{3}\right)$ & 1580,0 \\
\hline Água & \\
\hline Massa específica $\left(\mathrm{Kg} / \mathrm{m}^{3}\right)$ & 1000 \\
\hline
\end{tabular}

Fonte: Autores, (2018).

\section{III.3 MOLDAGEM E CURA}

A moldagem dos corpos de prova foi realizada de acordo com as especificações da NBR 5738 - Procedimento para moldagem e cura de corpos de prova, 2015. As dimensões das formas utilizadas foram de $10 \times 20 \mathrm{~cm}$. Após o período de $24 \mathrm{~h}$, os CP's foram retirados das formas e colocados no tanque de cura para as idades de 3, 7 e 28 dias.

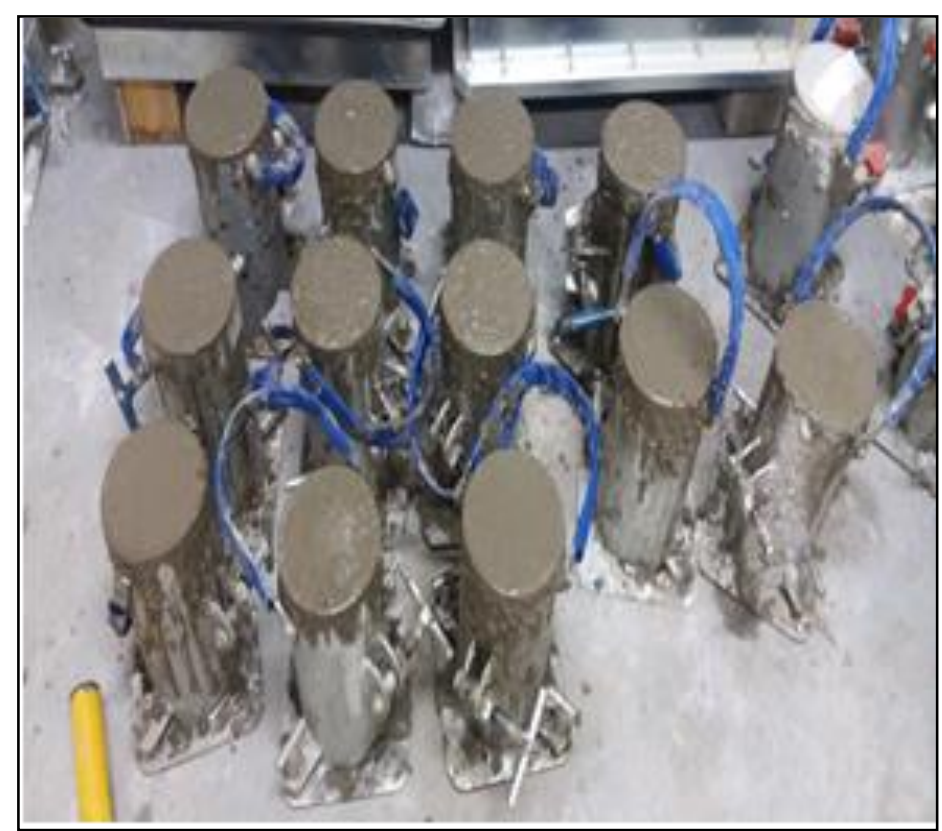

Figura 5: Moldagem dos corpos de prova. Fonte: Autores, (2018).

\section{III.4 RESISTÊNCIA À COMPRESSÃO}

A resistência à compressão foi realizada com o auxilio da prensa hidraúlica com painel digital. Abaixo, na tabela 2 encontram-se os resultados das idades de 7 e 28 dias. 
Tabela 2: Resultados obtidos da resistência à compressão aos 28 dias.

\begin{tabular}{|c|c|c|c|c|c|}
\hline \multirow{2}{*}{ Mistura } & \multicolumn{2}{|c|}{$\begin{array}{c}\text { Carga de ruptura } \\
\text { (Kgf) }\end{array}$} & $\begin{array}{c}\text { Resistência à } \\
\text { compressão } \\
\text { (MPa) }\end{array}$ & $\begin{array}{c}\text { Média } \\
\text { aos 28 } \\
\text { dias } \\
\text { (MPa) }\end{array}$ \\
\cline { 2 - 5 } & 7 dias & 28 dias & 7 dias & 28 dias & \\
\hline \multirow{2}{*}{$\begin{array}{c}\text { TR1-CP- } \\
0,0 \%\end{array}$} & 18100,0 & 19780,0 & 23,05 & 25,18 & \multirow{2}{*}{26,43} \\
\cline { 2 - 5 } & 19000,0 & 21730,0 & 24,19 & 27,67 & \\
\hline \multirow{2}{*}{$\begin{array}{c}\text { TR2-CP- } \\
0,5 \%\end{array}$} & 20700,0 & 20520,0 & 26,36 & 26,13 & \multirow{2}{*}{28,66} \\
\cline { 2 - 5 } & 20760,0 & 24500,0 & 26,43 & 31,19 & \\
\hline \multirow{2}{*}{$\begin{array}{c}\text { TR3-CP- } \\
1,0 \%\end{array}$} & 20240,0 & 28000,0 & 25,77 & 35,65 & \multirow{2}{*}{36,35} \\
\cline { 2 - 5 } & 20250,0 & 29100,0 & 25,78 & 37,05 & \\
\hline
\end{tabular}

Fonte: Autores, (2018).

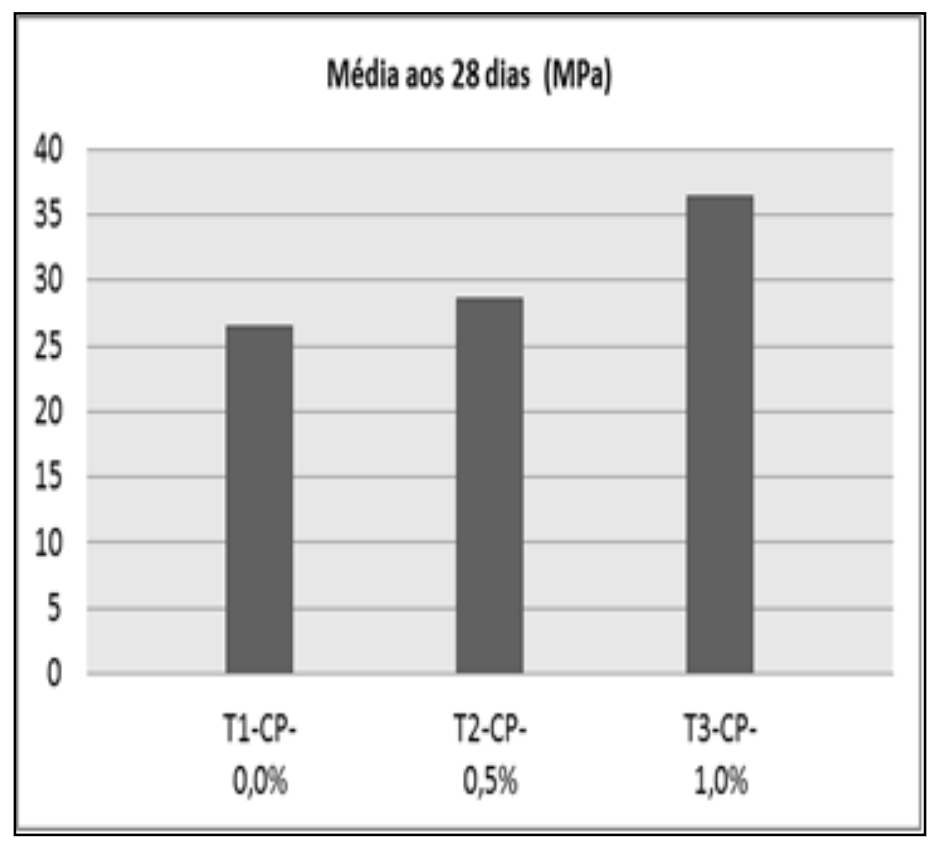

Figura 6: Gráfico da média dos resultados obtidos aos 28 dias. Fonte: Autores, (2018).

\section{III.4 ANÁLISE DO INDICADOR QUÍMICO DE FENOLFTALEÍNA}

A fenolftaleína é uma substância química que quando dissolvida em álcool produz uma coloração vermelha na presença de álcali, além de ser utilizada como indicador nas análises volumétricas. $\mathrm{O}$ pó dessa substância, para este projeto experimental, foi diluído em álcool etílico, 1:100 (1\% de fenolftaleína). $\mathrm{O}$ indicador químico fenolftaleína foi aplicado a partir da ruptura dos corpos de prova aos 28 dias e separados ao meio.

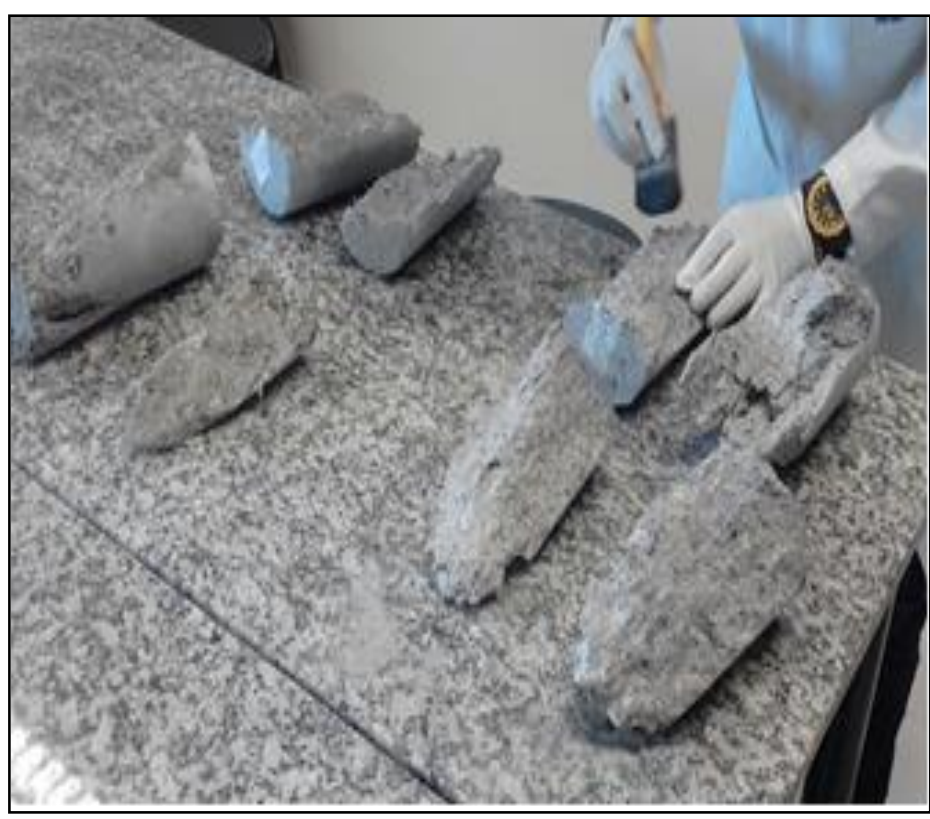

Figura 7: Limpeza dos CP's para aplicação do indicador químico de fenolftaleína.

Fonte: Autores, (2018).

A medição da carbonatação dar-se-á através da observação da coloração do indicador químico fenolftaleína em relação a sua profundidade e a sua absorção entre os poros. A quantidade do indicador químico foi de $5 \mathrm{ml}$ para cada lado fraturado.

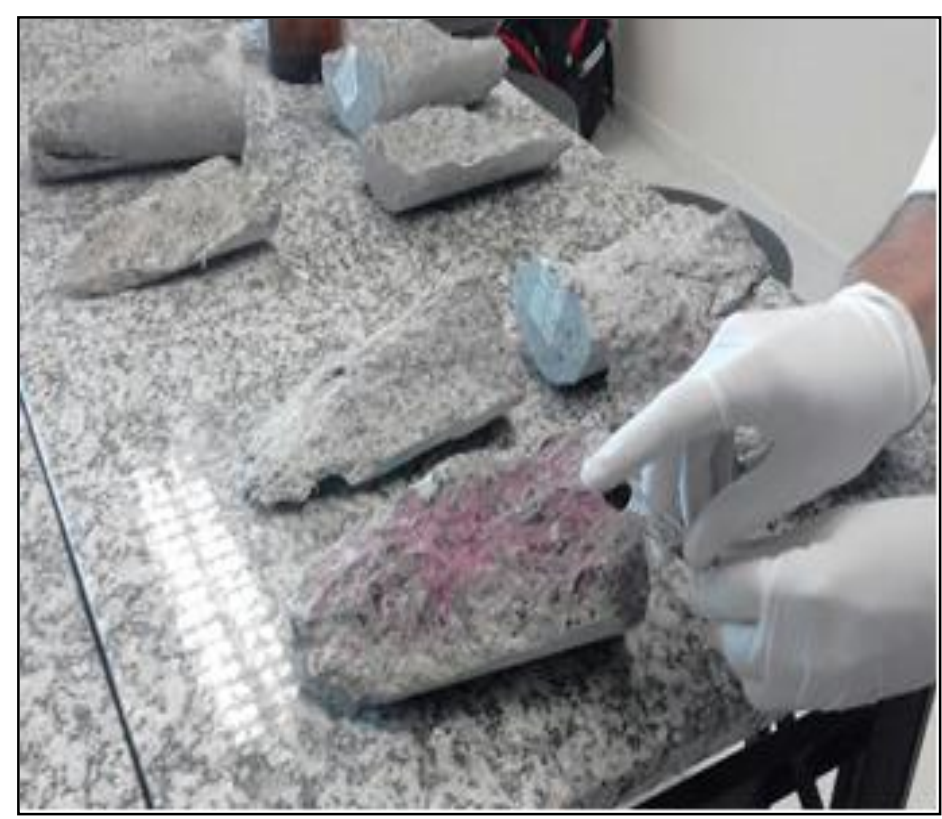

Figura 8: Início da aplicação do indicador químico de fenolftaleína nos corpos de prova. Fonte: Autores, (2018).

A profundidade da carbonatação foi medida em todas as faces do corpo de prova fraturado. A observação foi embasada conforme a idade de cura especificada pela norma. Os dias observados foram: 7, 28, 63, 91 e 120 dias. 


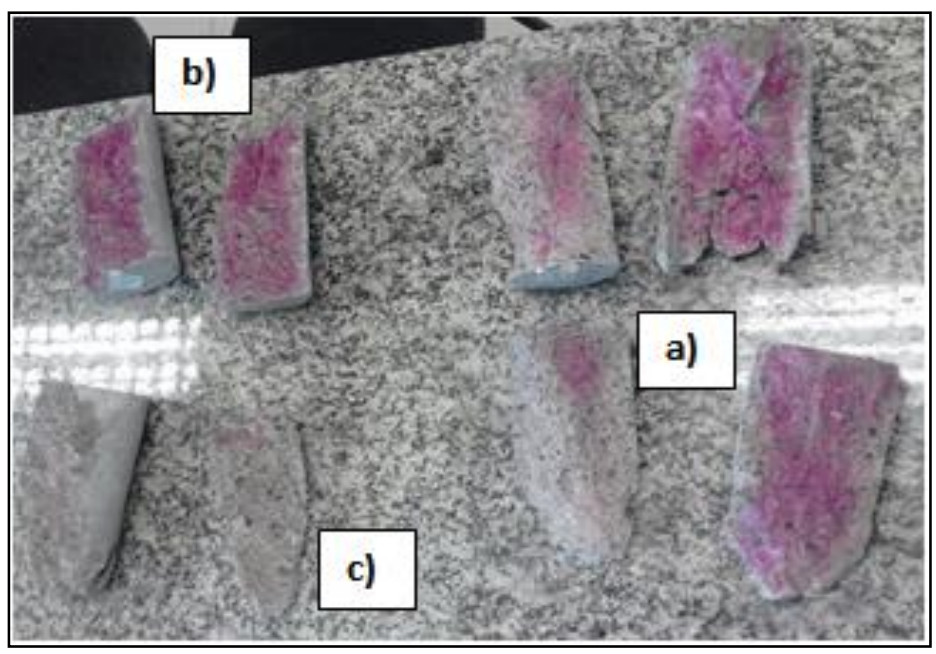

Figura 9: Corpos de prova após a aplicação do indicador químico de fenolftaleína. a) Traço com $0,0 \%$ de fibra; b) Traço com $0,5 \%$ de fibra; c) Traço com 1,0\% de fibra.

Fonte: Autores, (2018).

\section{RESULTADOS E DISCUSSÕES}

Os resultados obtidos através da observação após aplicação do indicador químico de fenolftaleína demonstram um processo acelerado, o que pode ser preocupante em termos de segurança, dependendo da função que esse material irá exercer. Abaixo, as figuras mostram o processo da carbonatação nos concretos: convencional, com $0,0 \%$ de fibra vegetal; com $0,5 \%$ de fibra vegetal e $1,0 \%$ de adição da fibra vegetal, conforme as idades estabelecidas.

Nota-se que as partes mais claras, quando o indicador químico de fenolftaleína se aspersa, já são indícios de carbonatação. As faces que mantem a cor de vermelho-marfim significam que as amostras de concreto não estão carbonatados.

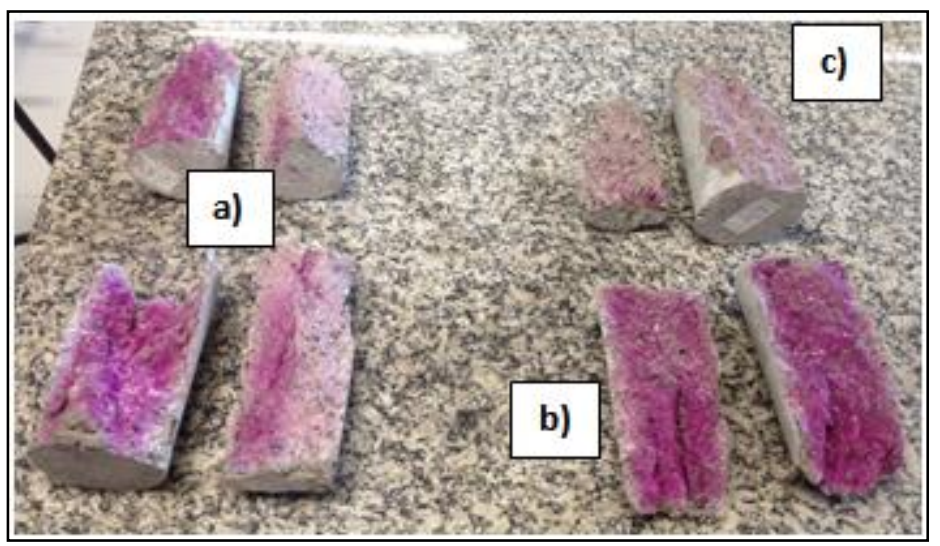

Figura 10: Observação dos CP's aos 7 dias após aplicação do indicador químico de fenolftaleína. a)Traço com $0,0 \%$ de fibra; b)Traço com $0,5 \%$ de fibra; c) Traço com $1,0 \%$ de fibra.

Fonte: Autores, (2018).

Na figura 10, observa-se que a coloração do indicador químico de fenolftaleína nas amostras a) e b), a cor é mais intensa quanto que na amostra c), onde encontra-se uma cor de intensidade leve apenas com 7 dias de exposição, do qual já podese afirmar que o processo de carbonatação já se iniciou.

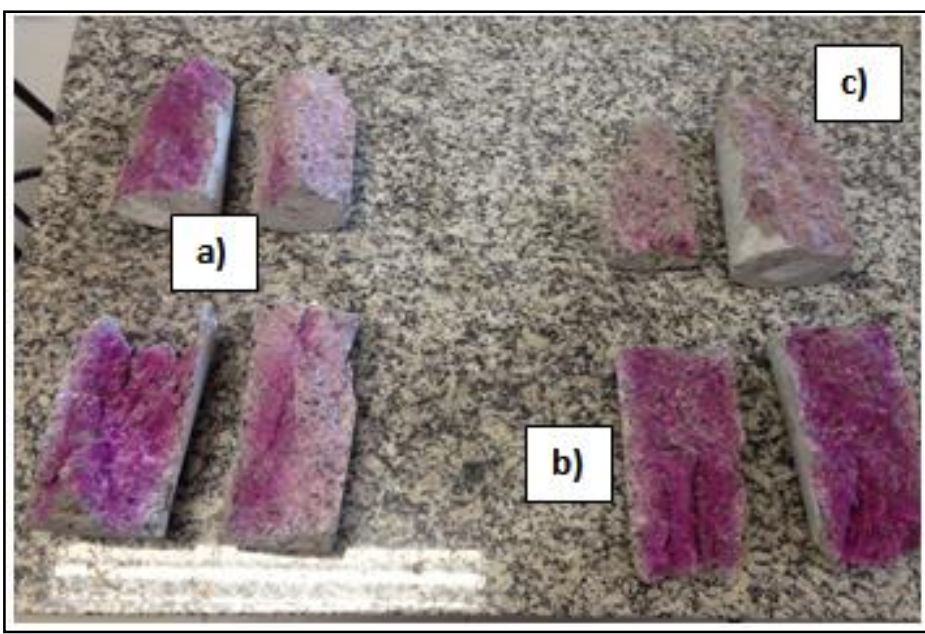

Figura 11: Observação dos CP's aos 63 dias após aplicação do indicador químico de fenolftaleína. a)Traço com $0,0 \%$ de fibra; b)Traço com $0,5 \%$ de fibra; c)Traço com 1,0\% de fibra.

Fonte: Autores, (2018).

Na figura 11, aos 63 dias de exposição dos materiais, a intensidade da cor vermelho-marfim continua mais perceptível nas amostras a) e b), podendo-se constatar que o processo do efeito da carbonatação ainda está lento. $\mathrm{Na}$ amostra a), existem cores mais claras, sendo que é o concreto convencional e na amostra b) a intensidade da coloração é mais intensa, enquanto na amostra c) o prcesso deu-se inicio desde o dia da aplicação.

Já na figura 12, a exposição dos materiais aos 120 dias ficou menos intensa a coloração nas amostra a) e b), praticamente se igualando a amostra c).

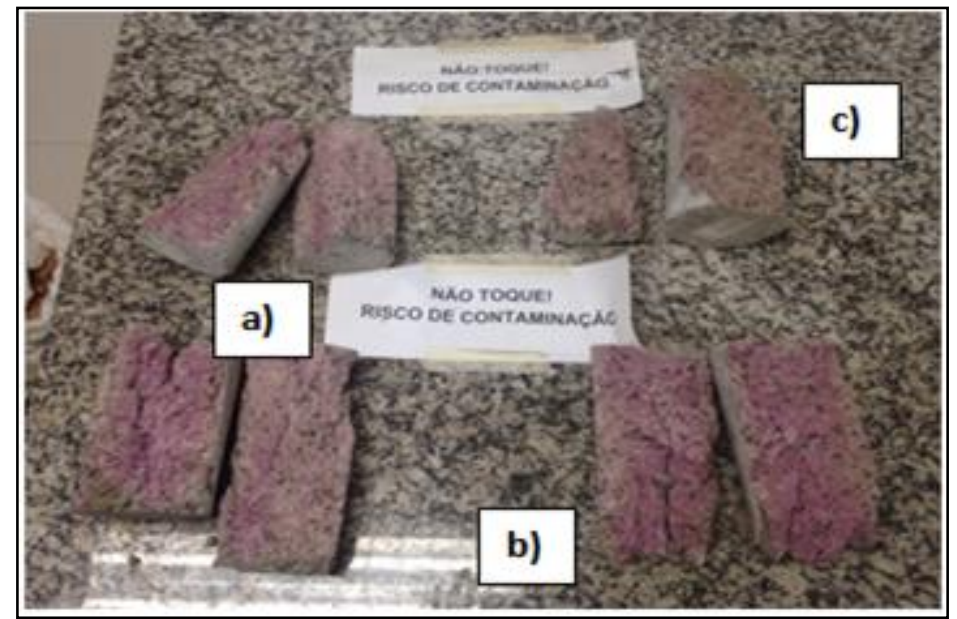

Figura 12: Observação dos CP's aos 120 dias após aplicação do indicador químico de fenolftaleína. a)Traço com $0,0 \%$ de fibra; b)Traço com 0,5\% de fibra; c)Traço com 1,0\% de fibra.

Fonte: Autores, (2018).

Todas as amostragens, de acordo com o processo de observação, desde a aplicação do indicador químico até o último dia de observação estabelecido, tiveram suas pastas de cimento carbonatadas, uns com o processo menos acelerado que os outros. Toda essa observação indica que o processo de carbonatação do concreto é bem mais rápido e o tempo de vida útil do concreto armado é bem menor do que se determina. Mas isso pode ser um indicador no processo da pasta de cimento ou da argamassa envolvendo inúmeros fatores dos quais pode ocorrer o efeito da carbonatação, não especificamente o concreto armado. 
O efeito da carbonatação é dado através da intensidade da coloração do indicador químico de fenolftaleína reage com a pasta de cimento. Quanto mais forte for a tonalidade da cor de vermelho-carmim no concreto, menor é o processo de carbonatação do concreto.

\section{CONCLUSÃO}

A carbonatação é um dos mecanismos mais ocorrentes de deterioração do concreto armado [15]. O processo, felizmente é lento e pode ser esclarecido por causa da hidratação crescente da pasta de cimento. O dióxido de carbono que atua no ar adentra nos poros úmidos do concreto e reage com o hidróxido de cálcio e forma o carbonato de cálcio, daí o nome de carbonatação. Este processo é seguido pela redução da alcalinidade do concreto juntamente com várias etapas envolvendo diversas reações secundárias [16].

Os resultados apresentados advertem o acompanhamento do avanço da aspersão do indicador químico de fenolftaleína no procedimento do efeito da carbonatação do concreto, conforme os dias de exposição e observação indicados em condições ambientais habituais do laboratório de Materiais de Construção e Técnicas Construtivas do Centro Universitário do Norte UNINORTE/ LAUREATE.

De acordo com a intensidade da cor das amostras acometidas com o indicador químico de fenolftaleína é possível determinar até onde a carbonatação ocorreu. A amostra c), com a maior porcentagem da fibra buriti $(1 \%)$ foi a que mais aspirou o indicador químico, enquanto as amostras a) e b) se mantiveram no processo lento do efeito da carbonatação. Então, pode-se afirma que o efeito da carbonatação foi maior na amostra c) com a porcentagem maior de fibra vegetal (buriti).

\section{AGRADECIMENTOS}

A todos que colaboraram com a pesquisa para a confecção deste artigo, em especial a coordenação do curso de engenharia civil do Centro Universitário do Norte (UNINORTE/ LAUREATE), pela disponibilidade do laboratório de Materiais de Construção, juntamente com o apoio técnico tanto dos professores responsáveis quanto ao técnico de laboratório Darlei A. Lavor.

\section{REFERÊNCIAS}

[1] REBMANN, M.S. Durabilidade de concretos estruturais com baixo consumo de cimento portland e alta resistência. Universidade de São Paulo, Escola de Engenharia de São Carlos, 2011.

[2] LABORATÓRIO NACIONAL DE ENGENHARI CIVIL LNEC F029 - Determinação da profundidade de carbonatação de betões, argamassas ou outros materiais cimentícios. Acesso em 15/ 01/ $18 . \quad$ Disponível em: $<$ http://www.ozdiagnostico.pt/fichas/1F\%20029.pdf>

[3] FERNANDEZBERTOS, M. et al. A review of accelerated carbonation technology in the treatment of cement-based materials and sequestration of $\mathbf{C O}_{2}$. Journal of Hazardous Materials, v. 112, n. 3, p. 193-205, ago. 2004.
PIZZOL, V. D. et al. Effect of accelerated carbonation on the microstructure and physical properties of hybrid fibercement composites. Minerals Engineering, v. 59, p. 101-106, maio. 2014.

[4] DE SOUZA, R. B. Estudo da retração em fibrocimento reforçado com fibra polimérica. São Paulo: Escola Politécnica da Universidade de São Paulo, 2014.

[5] DIAS, C. M. R. Efeitos do envelhecimento na microestrutura e no comportamento mecânico dos fibrocimentos. São Paulo: Escola Politécnica da Universidade de São Paulo, 2005.

[6] BRANDÃO, G. B., SOUZA, R. B. Efeito do empacotamento de partículas da fase matriz na carbonatação de compósito cimentício. Bonito. Anais... MS, 2015, 17 p.

[7] AGOPYAN, V.; SAVASTANO JUNIOR, H. Fibras vegetais como materiais de construção. In ISAIA, G. C. (editor) Materiais de construção civil e princípios de ciência e engenharia de materiais. São Paulo: Ibracon, 2007. 2v. 1721 p.

[8] FARUK, O.; BLEDZKI, A. K.; FINK, H. P.; SAIN, M. Biocomposites reinforced with natural fibers: 2000-2010, Prog Polym Sci, 2012.

[9] SILVA, E.; MARQUES, M.; FORNARI JUNIOR, C. Aplicação de fibra de coco em matrizes cimentícias. In SILVA et al. (editor), Revista electronica em gestão, educação e tecnologia ambiental. Bahia: REGET/ UFSM, 2012. 8v. 1555-1561 p. Acesso em 15/ 01/ 2018. Disponível em: http://cascavel.ufsm.br/revista/ojs2.2.2/index.php/reget/index

[10] CATTANI, I. M; BARUQUE-RAMOS, J. Fibra de buriti (mauritia flexuosa mart.) e aplicações em produtos têxteis. $2^{\circ}$ congresso científico têxtil e de moda, CONTEXMOD, 2014. São Paulo-SP.

[11] FILHO, E. A. R. B. Análise do desempenho físico-mecânico do concreto convencional de cimento Portland com substituição parcial das fibras da palmeira de buriti $0.3,0.5$ e $1 \%$. Manaus. Amazonas, 2017.

[12] MEHTA, P. K.; MONTEIRO, P. J. M. Concreto: estrutura, propriedades e materiais. São Paulo: PINI, 1994, 573 p.

[13] SCHRODER, F.; SMOLCZ YK, H. G. Carbonation and protection against steel corrosion. In: Fith Int. Symp. Chemistry of Cement. vol. 4, p. 188-198, Tokyo, 1968.

[14] TUUTTI, K. Corrosion of steel in concrete. Sweden: CBI, 1982. 468p.

[15] WERLE, A.P., TROIAN, A., KAZMIERCZAK, C.S., KULAKOWSKI, M.P. Carbonation in concrete with coarse recycled concrete aggregates. In: Conference Proceedings of 12th International Conference on DBMC, 4., 2011, Porto.

Proceedings... Porto: FEUP Edições, 2011, p. 1677-1684.

[16] CASCUDO, O. O Controle da Corrosão de Armaduras em Concreto: Inspeção e Técnicas Eletroquímicas. 1. ed., São Paulo: Ed. Pini, 1997. 237 p. 